\title{
Article \\ Organizational Structure and Artificial Intelligence. Modeling the Intraorganizational Response to the AI Contingency
}

\author{
Ihor Rudko ${ }^{1}$, Aysan Bashirpour Bonab ${ }^{2}$ and Francesco Bellini ${ }^{3, *}$ \\ 1 Eurokleis srl, 00136 Roma, Italy; ihor.rudko@eurokleis.com \\ 2 Department of Economics and Law, University of Cassino, 03043 Cassino, Italy; \\ aysan.bashirpourbonab@unicas.it \\ 3 Department of Management, Sapienza University of Rome, 00161 Roma, Italy \\ * Correspondence: francesco.bellini@uniroma1.it; Tel.: +39-348-380-8226
}

check for

updates

Citation: Rudko, I.; Bashirpour Bonab, A.; Bellini, F. Organizational Structure and Artificial Intelligence. Modeling the Intraorganizational Response to the AI Contingency. J. Theor. Appl. Electron. Commer. Res. 2021, 16, 2341-2364. https:// doi.org/10.3390/jtaer16060129

Academic Editor:

Eduardo Álvarez-Miranda

Received: 5 August 2021

Accepted: 7 September 2021

Published: 13 September 2021

Publisher's Note: MDPI stays neutral with regard to jurisdictional claims in published maps and institutional affiliations.

Copyright: (c) 2021 by the authors. Licensee MDPI, Basel, Switzerland. This article is an open access article distributed under the terms and conditions of the Creative Commons Attribution (CC BY) license (https:/ / creativecommons.org/licenses/by/ $4.0 /)$.
Abstract: Different and profound are the consequences of the further development of artificial intelligence (AI) on society. One of the manifestations of the upcoming changes is the plethora of novel ways in which companies may organize labor and capital. So far, the influence of AI on organizational structure has been mainly studied from either a technological or a broader decision-making perspective. Our paper provides a unique take on the topic, emphasizing the distinctive role of human agency and its function in the upcoming AI-driven organizational changes. Relying on the existing academic literature, we theorized a set of hypotheses concerning best fits to the AI contingency on both macro and meso-organizational levels. To test whether the hypothesized changes might encounter organizational inertia or resistance from jobholders, multiple correspondence analysis (MCA) was applied to the online survey results. Four types of current and potential jobholders were distinguished according to their explicit attitudes towards hypothesized organizational changes: skeptics, doubtful skeptics, optimists, and doubtful optimists, the latter consisting primarily of emerging adults. Finally, we developed a model of intraorganizational response to the AI contingency based on four theoretical groups of individuals, as determined by the analysis. Our findings showed doubtful optimists to be the most important group, able to set organizational trends and positively influence skeptics and doubtful skeptics. Accordingly, promoters of AI-driven organizational changes are advised to design their communication efforts around emerging adults. As the survey was conducted amid the COVID-19 pandemic, its sociological and managerial implications are relevant to the looming reality of the postpandemic world.

Keywords: artificial intelligence; contingency theories; organizational structure; explicit attitudes; cultural intermediaries; organizational change

\section{Introduction and Basic Assumptions for the Model's Development}

Artificial intelligence is here to stay, whether we want it or not. As a technology, it is neutral, as all technologies are, according to Kranzberg [1]. Its usage, however, will eventually define the socioeconomic implications of its further development. Be it the Second Digital Revolution or Industry 4.0-more specific to the secondary sector-artificial intelligence will play a pivotal role in its definite affirmation [2,3]. More so, its potential uses transcend relative periods of social stability, as AI-based technologies find countless applications even in times of higher social distress, such as pandemics $[4,5]$.

The concept of artificial intelligence is complex, ranging from mathematical theorizations to philosophical considerations of the highest order [6]. Moreover, the notion of AI is not independent of the development of contingent technologies, first and foremost cloud computing, upon which artificial intelligence increasingly relies [7]. For the scope of the theoretical model developed in the paper, we adopted the more practical notion of AI. We considered artificial intelligence mainly as an existing or an upcoming set of technologies, both as software and hardware solutions endowed with some form of simulated human 
intelligence. In this way, we target the present day's problems and avoid typical futuristic speculations that frequently surround issues of high-level artificial intelligence and full automation of labor [8].

Within the perspective of contingency theories, artificial intelligence emerges as one of the most relevant factors of internal and external environments and the critical technological factor for most organizations worldwide [9-11]. According to the core notion of contingency theories, a company should seek a fit between relevant contingencies and its internal and external organizational structure to gain a sustainable competitive advantage [12,13]. As the perspective suggests, only when an organizational structure fits the AI contingency well is the company's long-term viability possible.

Although the topic of AI within the organizational framework is becoming increasingly popular (as the breakdown by years of a simple query ((TITLE-ABS-KEY (ai OR artificial AND intelligence) AND TITLE-ABS-KEY (organizational AND design OR organizational AND theory OR organizational AND structure) ) AND (LIMIT-TO (DOCTYPE, "ar") ) AND (LIMIT-TO ( SUBJAREA, "BUSI" ))) on Scopus reveals), we found little evidence regarding the influence of artificial intelligence on individual structural variables of an organization. Indeed, most of the 47 articles produced by the query (as of August 2021) revolved around either technological aspects of intelligent technologies or decision making in the broader sense. In addressing this research gap, our paper represents the first attempt to study the interplay between AI and organizational structure as broken down by its single micro and meso components.

The regulation and fine-tuning of external organizational variables in response to the AI contingency are not analyzed in the paper. Although the implications of large-scale adoption of artificial intelligence on the macro-organizational structure might be significant, they are not considered either-as the choice of organizational form (typical of a macrolevel of analysis) directly relies on organizational choices at the micro and meso-organizational levels [14]. Therefore, the best organizational fits are hypothesized only by regarding the degree of relevant micro and meso-organizational variables.

In accordance with the research gap, the first research question was formulated as follows:

- RQ1: What are the plausible influences of the development of AI on the single organizational variables of micro and meso levels of analysis?

Our second research question was agent-centric as it derived from the recognition that individuals are not passive in relation to structural changes, and their agency may also substantially shape structural characteristics [15]. Indeed, employees' inertia and resistance to change may halt the necessary adaptive changes of the organization. To better understand the attitudes of employees towards hypothesized AI-driven organizational changes, the second research question was formulated as follows:

- RQ2: How do employees vary according to their explicit attitudes towards organizational changes related to the increasing development and adoption of AI by businesses?

The third research question inevitably arose from the second one:

- RQ3: What is the best strategy to implement AI-driven changes in the organization given the potential of organizational inertia and resistance resulting from employees negative attitudes towards novel intelligent technologies?

Given the limited state of the modern-day organizational literature on the topic, whenever not directly available, the evidence for the hypothetical best fits to the AI contingency was inferred from the vast body of academic literature concerning the influence of information technologies (IT) on the organizational variables of firms. We assume such a generalization is well-grounded. AI-based technologies do present some novel and unique characteristics [16]. They are, nonetheless, ascribable to the more general category of information technologies [17]. 
As for the consequences of the development and the increasing adoption of AI-based software and hardware by companies, we assumed that the hypothesized socioeconomic outcomes for the upcoming decade will not be overly pessimistic [18]. The assumption is concordant with the recent report of Accenture [16], which unlike the statistical survey of AI experts conducted by scholars from Oxford and Yale [19], offers a brighter view of the near future. According to the authors of the report, intelligent agents are not likely to substitute for human employees. On the contrary, Daugherty and Purdy [16] expect a surge in integrating the skills and capabilities of human operators with the precision and insights of simulated minds. Nevertheless, it is difficult to avoid a cautionary tone in hypothesizing the outcomes of the further development of artificial intelligence. Unlike the enabling technologies of the past technological revolutions, AI presents characteristics of the ultimate job replacer. For the first time in history, a technology holds relevant ontological qualities of both labor and capital [16]. This dimorphic nature makes artificial intelligence a unique factor of production with significant replacement potential. In the latter case, the long-run trend may indeed be that of full automation of labor, grimly predicted by the scholars of Oxford and Yale [19].

Finally, theoretical notions and all the assumptions used in the paper may be applied to all kinds of formal organizations, although with some reservations. Nevertheless, we developed the model with a profit-oriented privately-owned organization in mind, typical of a capitalistic society. Therefore, we use the terms 'organization' and 'company' interchangeably.

According to the first research question, in the following Section Two, the main hypotheses concerning the influence of AI on the different structural characteristics of organizational design are generated by means of the review of the available literature on the topic. Next (Section Three), in accordance with the second research question, to understand the attitudes of jobholders towards hypothesized AI-driven organizational changes, we introduce the survey through which such attitudes were measured. Multiple correspondence analysis (MCA) was then performed to understand the clustering of the respondents according to their attitudes and demographic characteristics. The third research question is answered in Section Four, where the model of intraorganizational response to the AI contingency is proposed, based on the results of MCA and the sociological analysis of the resultant social groups.

Our findings show that the explicit attitudes towards AI-driven organizational changes vary along two dimensions: affect (how positive or negative are the attitudes) and intensity (how strong are the attitudes). Accordingly, the existence of four classes of jobholders was hypothesized: skeptics, doubtful skeptics, optimists, and doubtful optimists. The sociological analysis of the four categories revealed doubtful optimists to be the most critical social group in terms of effort and organizational resources that managers should spend in order to enable the organizational changes. The latter represents the main practical implication of the paper. On the other hand, academic interest is closely related to the research gap. Indeed, our study is the first to address the issue of AI contingency in a structural manner, investigating its influence on single organizational variables, on both micro and meso levels of analysis.

\section{Best Organizational Fits to the AI Contingency. Evidence from the Literature}

\subsection{Micro-Organizational Variables. Job Variety and Job Richness}

Further implementation of technologies based on deep learning, machine learning, and other types of artificial intelligence will not necessarily eliminate existing jobs in their entirety. While some of the simpler jobs that do not require significant intellectual effort, empathy, or intuition may disappear, and new jobs related to the emerging technologies will eventually appear [20-22], the main tendency of the following years will be the redesign of existing jobs to accommodate technological advances. 
The 2020 Deloitte report sums up the issue perfectly: "cutting costs by eliminating jobs is not the only path available for AI. Organizations face a fundamental choice: whether to use AI solely to automate tasks formerly performed by people, or to use it to assist workers as well" [23] (p. 54). The report introduces the concept of 'super job', an integration of tasks and responsibilities from multiple traditional jobs through synergies between human operators and AI. Overall, the authors are confident that rather than eliminating jobs, artificial intelligence will eliminate tasks from jobs [24]. Indeed, most of the automation seems to occur at the task level, not at the level of a job itself [25].

The tendency towards job reorganization rather than automation is confirmed by Brynjolfsson et al. [26]. The authors acknowledge growing concerns about the impact of machine learning and deep learning algorithms on employment. Yet, they conclude that the typical apocalyptic view of 'full automation of labor' is misleading. According to the authors, even if the current simple machine learning technologies are potentially pervasive, their adoption will most likely lead to the reorganization of jobs rather than the elimination of jobs. "The focus of researchers, as well as managers and entrepreneurs," claim the authors "should be not (just) on automation, but on job redesign" [26] (p. 44).

In providing his perspective on the paper of Brynjolfsson et al. [26], Irving WladawskyBreger, a Research Affiliate at MIT's Sloan School of Management, suggests that some of the tasks "are more susceptible to automation, while others require judgment, social skills, and other hard-to-automate human capabilities" and that "just because some of the activities in a job have been automated, does not imply that the whole job has disappeared. Automating parts of a job will often increase the productivity and quality of workers by complementing their skills with machines and computers, as well as enabling them to focus on those aspects of the job that most need their attention" [27]. Indeed, the current wave of automation concerns mainly the simplest of tasks, already dehumanizing at their core, tasks that can be easily delegated to artificial agents. One recent example of tasks restructuring is given by the automation of authentication processes, potentially invaluable in the context of both private and public spaces (e.g., hospitals, schools, and universities) [28].

These arguments are closely related to the changes alongside the vertical axis of job design. We hypothesize that while the jobs are becoming less broad horizontally, AI may enrich them significantly by increasing the amount of autonomy and control each human operator detains in their job [20,29].

In their detailed analysis of the impact on the workplace of robotics and artificial intelligence conducted by IBA Global Employment Institute, the authors predict that one of the main changes at individual working places caused by the growing adoption of intelligent agents will be the increased autonomy of the single employee. "The cross-linking of single employees by new technologies allows easier communication and enables a better exchange of information," state the authors, "employees will ask for more autonomy and will be focused on many different career paths—-sometimes in very different branches or countries-rather than having a 9-to-5 job" [30] (p. 52).

Another critical aspect of a micro-organizational design is psychological sustainability at the workplace [31,32]. The issue closely related to the introduction of AI in an organization concerns technostress [32]. Indeed, job risk and insecurity, underperformance, and the potential work overload, tightly connected to digitization, are looming over the psyche of a modern-day employee. One of the possible ways to eliminate the undesirable psychological effects that may follow the reduction in job variety, such as monotony and mental exhaustion, is to counterbalance the reduced scope of the job with more job enrichment [33]. On the other hand, an organization should actively undertake upskilling initiatives to ensure its employees are comfortable with understanding and using novel intelligent technologies [29].

\subsection{Horizontal Axis of Meso-Organizational Specialization. Span of Control}

No specific accounts were found in the existing organizational literature on how artificial intelligence may affect the span of control. It is not surprising, though, as according to 
Galbraith [34] (p. 36), when "the Conference Board, a group that conducts research on organizational structures, surveyed spans of supervision among its members the distribution ranged from 0 to 127 people. The distribution was trimodal, with modes at 7, 17, and 75." The trimodal distribution suggests there may not exist a dominant factor contributing to the way the optimal size of organizational units is determined. According to the author, "the trend today is toward much wider spans and flatter structures" [34].

We hypothesize there may not exist a specific organizational fit in terms of larger or smaller organizational units as a universal best response to the AI contingency. In addition, other contingencies might play an equally important role in the choice. However, given the scarce state of the academic literature on the subject, we think a further exploration of the topic is needed to formulate an adequate and credible hypothesis.

\subsection{Vertical Axis of Meso-Organizational Specialization. Decentralization and Chain of Command}

In terms of centralized vs. decentralized rhetoric, the latter approach seems to be the leading organizational trend nowadays. Together with other innovative organizational tendencies, it gives birth to novel organizational forms [35]. Among all the contributing factors, IT is frequently mentioned as one of the most significant facilitators of the growing degree of decentralization (or, vice versa, decreasing degree of centralization) [36]. The notion of decentralization is also closely related to empowerment $[37,38]$.

In his 1999 paper, Malone [39] (p. 141) argues that "greater decentralization in business (including 'empowerment') is a response to fundamental changes in the economics of decision-making that are enabled by new information technologies," and also "as communication costs fall, independent decentralized decision-makers are replaced, first by centralized decision-makers, and then by connected decentralized decision-makers," suggesting that "empowerment is not just a fad, but likely to become even more important in the next century."

According to the author, most managers think of decentralization and empowerment issues as related to some minor shifts within the power structure of a company that remains hierarchically centric. However, "to fully exploit the possibilities of new information technologies," there is a need for a change within people's mindsets and therefore the will to rethink typical organizational structures to include what he calls "radically decentralized organizations" as novel models of organizing work in the 21st century [39] (p. 141).

As for the more specific contributions concerning AI and decentralization, Mohanty and Vyas [40] argue that artificial intelligence, together with the development of the Internet of Things and Blockchain technology, will lead to the increase in what authors call 'decentralized autonomous organizations'.

Another critical variable of the vertical specialization of the meso-organizational level of design is the chain of command (expressed as the number of hierarchical levels) [41]. Once again, the broader academic literature concerning the influence of IT on the organizational structure is most helpful here, given the substantial lack of AI-related academic literature on the topic.

The so-called delayering represents one of the most critical aspects of novel organizational tendencies [42]. The excessive number of hierarchical levels is rarely viewed in a positive light. It has been frequently connected with rigidity, less responsiveness to change, high structural costs, communication problems, and higher communication costs, detriment in the quality of decision making, responsibility issues, and reduced motivation [14].

More than 30 years ago, Lawler foresaw IT as one of the most important substitutes for the hierarchy [43], capable of replacing most of its typical functions. Considering the year when the author proposed his list of substitutes, it is hardly surprising that artificial intelligence was not considered one of them, or - which is more likely - that Lawler had implicitly incorporated it into the broader IT category. However, it is obvious now that AI algorithms go way beyond simple information processing [44]. To make decisions and to assign tasks no longer seems way beyond the reach of modern-day AI technologies. The 
same will likely become true for the more 'humane' functions of the hierarchy: guiding and motivating [45]. It is reasonable to assume that AI might become the ultimate substitute of the hierarchy contributing noticeably to the overall passage from tall to flat organizational structures.

A more recent contribution to the topic is provided by Fountaine et al. [46]. In their article, authors claim that "as AI tools spread throughout the organization, those closest to the action become increasingly able to make decisions once made by those above them, flattening organizational hierarchies" [46].

\subsection{Coordination Mechanisms of Meso-Organizational Specialization. Standardization, Formalization, and Incentives}

According to Schilling [47], a combination of standardization and formalization defines the difference between mechanistic and organic organizational structures. More specifically, a high degree of standardization paired with a high degree of formalization leads to highly mechanistic organizational structures, while a low degree of formalization paired with a low degree of standardization defines organic organizational structures.

Traditionally, mechanistic structures are more desirable for higher productivity and efficiency and are better suited to reap the benefits of the economies of scale. However, one of the major drawbacks of such structures is their propensity to lock down the organization, making it very hard to foster innovations and respond to the external environment readily through organizational change [48,49].

This perspective is helpful in analyzing the influence of AI contingency on the degrees of standardization and formalization. According to Bauman, we live in a highly dynamic world, in which traditional values are now quickly eroding, and consumption became the need and desire in itself as opposed to the mere way of satisfying existing needs and desires on the marketplace $[50,51]$. For Bauman, these inner psychological changes complemented by increased globalization and the shortening of the products' turnover on the worldwide scale outline a new stage of modernity which he calls 'liquid modernity'. According to the sociologist [52], this new historical stage is mainly defined by increased individualization accompanied by feelings of uncertainty and existential ambivalence. Ulrich Beck further integrates the argument. He defines a closely related concept of 'risk society'. According to Beck [53], a risk society is increasingly concerned with the future, which produces and reproduces the notion of risk.

Burns and Stalker, two of the founding fathers of contingency theories, emphasize that the efficiency of the organizational structure largely depends on the dynamism of the external environment. For the two scholars, if the environment is stable, the mechanistic organizational structure suits a company the most [54]. If the environment is marked by a high degree of volatility, dynamism, and uncertainty, an organic structure works the best [55]. By combining a sociological perspective on the state of modern-day society and the conclusions of Burns and Stalker [54,55] on the choice between mechanistic and organic structures, it is easy to grasp how further development of AI on a worldwide scale may potentially influence the organizational structures of companies. If the preoccupations of Beck and Bauman are correct, artificial intelligence, given its disruptive nature [56], will significantly contribute to the growing uncertainty of the world. The growing risk and dynamism of the external environment will undoubtedly lead to an increasing number of more flexible change-oriented organic structures across all types of companies in the three sectors of the economy. Thus, we hypothesize that the primary influence of AI on standardization and formalization is the reduction in the degree of both, which in turn leads to the adoption of more environmentally responsive organic organizational structures.

Incentives represent another important coordination mechanism of mesovertical specialization. There exist different ways in which incentives may be implemented, from monetary ones $[57,58]$ to the possibility of hierarchical growth and the increased perception of one's contribution to overall organizational output $[59,60]$. Artificial intelligence will presumably play a significant role in the definition of one specific incentive. The incentive 
mainly reflects the long-lasting trend of the decrease in the average number of working hours.

Unlike other types of incentives, the reduction of the average number of working hours is an almost universal trend that rarely depends on managerial decisions but merely follows the technological progress and normative choices of different countries [61]. With the further adoption of AI by companies, the extent and nature of such reduction (including greater temporal flexibility and autonomy) may become more radical than ever, given the high degree of sustainability between human workers and intelligent agents [30].

If not accompanied by a reduction in wages, the decrease in the weekly workload may have numerous psychological benefits leading to a better work-life balance, increased productivity, and an increase in the motivation of employees $[30,62,63]$.

\subsection{Overview of the Formulated Hypotheses}

Artificial intelligence constitutes an important contingency in both its technological aspects and as a more general external environment of organizations. Moreover, it is going to become even more relevant as the increasing number of scholars emphasize the crucial role of AI in the upcoming technological revolution [3,64-66]. A company must strive for the right organizational fit with the AI contingency to reap the long-lasting competitive advantage of the upcoming economic, technological, and societal changes.

The summary of the hypothesized best responses to the AI contingency in terms of specific degrees of key intraorganizational variables is shown in Table 1 . These hypotheses formed the basis for the development of the generalized model of intraorganizational response to the AI contingency explored in the following two sections. The hypotheses are derived from the literature review and are, therefore, exogenous to our model.

In a strict sense, the modeling reported in the following two sections concerns the study of the explicit attitudes of jobholders towards the proposed hypothetical AI-driven changes within an organization. The methodological core of the study is rooted in inductive reasoning. However, we did not approach the modeling in an entirely atheoretical manner. Consequently, four endogenous hypotheses were a priori postulated:

Hypothesis 1 (H1). Most jobholders (current or potential) have primarily positive explicit attitudes towards the proposed organizational changes caused by the further development and adoption of AI by organizations.

Hypothesis 2 (H2). Albeit positive, the explicit attitudes of jobholders (current or potential) towards decreasing horizontal division of labor are less strong than those concerning the vertical division of labor.

Hypothesis 3 (H3). Jobholders (current or potential) have no clear preferences towards the degree of the span of control.

Hypothesis 4 (H4). Among all the jobholders (current or potential), emerging adults play the most crucial role in terms of their ability to transmit positive attitudes towards proposed organizational changes and to help enable organizational changes successfully. 
Table 1. Hypothesized best fits to the AI contingency.

\begin{tabular}{|c|c|c|c|c|}
\hline Intraorganizational Level & Organizational Variable & $\begin{array}{l}\text { The Best Fit to AI Contingency (in } \\
\text { Terms of the Degree Assumed by } \\
\text { an Organizational Variable) }\end{array}$ & Main Reason & References \\
\hline $\begin{array}{c}\text { Micro (horizontal division } \\
\text { of labor) }\end{array}$ & Variety/scope of job & Low & $\begin{array}{l}\text { Initially, AI will not eliminate } \\
\text { jobs but remove tasks } \\
\text { from jobs }\end{array}$ & [20-28] \\
\hline $\begin{array}{c}\text { Micro (vertical division of } \\
\text { labor) }\end{array}$ & Richness/autonomy of job & High & $\begin{array}{l}\text { Increased job autonomy is the } \\
\text { most efficient way to } \\
\text { compensate for the reduction } \\
\text { in job variety }\end{array}$ & {$[20,29-33]$} \\
\hline $\begin{array}{l}\text { Meso (horizontal axis of } \\
\text { specialization) }\end{array}$ & $\begin{array}{l}\text { Span of control (size of } \\
\text { organizational units) }\end{array}$ & The effect of $\mathrm{AI}$ is unclear & $\begin{array}{l}\text { The optimal size of } \\
\text { organizational units is the } \\
\text { result of the interplay of } \\
\text { multiple different factors }\end{array}$ & [34] \\
\hline $\begin{array}{l}\text { Meso (vertical axis of } \\
\text { specialization) }\end{array}$ & Degree of centralization & Low & $\begin{array}{l}\text { Decentralization is the major } \\
\text { organizational trend } \\
\text { significantly influenced by the } \\
\text { development of IT }\end{array}$ & [35-40] \\
\hline $\begin{array}{l}\text { Meso (vertical axis of } \\
\text { specialization) }\end{array}$ & $\begin{array}{l}\text { Number of hierarchical } \\
\text { levels (length of the chain } \\
\text { of command) }\end{array}$ & Low & $\begin{array}{l}\text { Given its intrinsic properties, } \\
\text { AI may be considered the } \\
\text { perfect substitute for the } \\
\text { hierarchy }\end{array}$ & {$[14,41-46]$} \\
\hline $\begin{array}{l}\text { Meso (coordination } \\
\text { mechanism) }\end{array}$ & Standardization & Low & $\begin{array}{l}\text { As a set of disruptive } \\
\text { technologies, AI is } \\
\text { contributing to the uncertainty } \\
\text { of the economy; therefore, } \\
\text { organic structures will be more } \\
\text { required }\end{array}$ & {$[47-56]$} \\
\hline $\begin{array}{l}\text { Meso (coordination } \\
\text { mechanism) }\end{array}$ & Formalization & Low & $\begin{array}{l}\text { As a set of disruptive } \\
\text { technologies, AI is } \\
\text { contributing to the uncertainty } \\
\text { of the economy; therefore, } \\
\text { organic structures will be more } \\
\text { required }\end{array}$ & [47-56] \\
\hline $\begin{array}{l}\text { Meso (coordination } \\
\text { mechanism) }\end{array}$ & Incentives & High & $\begin{array}{l}\text { Incentives mainly concern the } \\
\text { reduction of the average } \\
\text { number of working hours per } \\
\text { week (assuming the same } \\
\text { wage). AI may significantly } \\
\text { contribute to the trend given } \\
\text { the high degree of } \\
\text { sustainability between simple } \\
\text { human tasks and the } \\
\text { intelligent technology }\end{array}$ & {$[30,57-63]$} \\
\hline
\end{tabular}

\section{Understanding the Attitudes of Jobholders towards Hypothesized Organizational Changes}

\subsection{Operationalization and Data Gathering}

Understanding the attitudes of jobholders, both current and potential, towards imminent changes caused by $\mathrm{AI}$ is a major step towards the theorization of the optimal change implementation strategy. If people within the organization resist the changes, the organization is not likely to benefit any of them. Blind implementation alone is dangerous and unwise. To investigate the nature and intensity of employee's attitudes towards hypothesized organizational changes, we designed a brief crosssectional survey. The survey consisted of twelve questions, five of a generic demographic nature and seven (one to one) related to respondents' perception of proposed organizational changes.

We decided to put no restrictions on respondents' age and working status (working/nonworking), as even younger and currently unemployed/nonworking individuals may hold strong attitudes towards hypothesized organizational changes. The sociological reasoning behind the decision is related to the notion of habitus [67] developed by Bour- 
dieu [68]. Habitus can be described as "the embodiment of social structures and history in individuals" and "a set of dispositions, internal to the individual, that both reflect external social structures and shapes how the individual perceives the world and acts in it" [69] (p. 48). Given that an individual's primary habitus is mainly developed during childhood [68], it is reasonable to assume that the preferences towards certain types of working environments are deeply rooted within respondents and are unlikely to change passively. No restrictions were also put on the respondents' origin to make the sample as broad as possible and to better capture the ubiquitous nature of the hypothesized organizational changes.

A total of 325 individuals completed the survey. Among those, the majority belonged to the 18-30 years old category $(63.7 \%)$. People who were 30 years old and beyond constituted $25.8 \%$ of the sample. An approximately equal number of males and females participated in the survey. Most respondents came from Europe (45.2\%), followed by Asia $(24.3 \%)$, and North America (19.4\%). A total of 46.8\% were currently working, while the rest were not working at the moment. Finally, almost $70 \%$ of respondents were students, while the rest were not. No personal information that might lead to the identification of the respondents was at any point gathered during the survey. The anonymity of the respondents was respected. Seven hypotheses-related questions were carefully formulated to unambiguously communicate the nature of the hypothesized organizational changes to respondents, according to the proposed best fits summarized in Table 1 . We structured the answers for this block of questions in the form of a Likert scale ('yes', 'more yes than no', 'more no than yes', 'no', denoting strongly positive, weakly positive, weakly negative, and strongly negative attitudes, respectively). The even number of categories was not accidental but served a clear purpose of preventing individuals from choosing neutral responses such as 'I do not know'. This served to diminish the likelihood for the respondents to select 'easy' answers and conclude the survey as soon as possible, given that no incentives were offered to respondents for answering the questions diligently. Each response set was coded as a character variable in RStudio, denoting, respectively, the attitudes towards lower scope jobs (scope), richer jobs (richness), a greater span of control (size_of_ou), greater decentralization (decentralization), a lower chain of command (numb_of_levels), more organic structures (organic), and greater nonmonetary incentives (incentives). Standardization and formalization were treated as a single organizational variable, given that a high degree of both typically leads to organic organizational structures [47]. The direct measurement of attitudes is commonly practiced in organizational psychology and related disciplines [70,71]. Nevertheless, only explicit attitudes can be effectively measured by employing a survey. To measure implicit attitudes would require a more elaborated resource-heavy methodology, such as implicit association tests (IAT) [72]. As explicit attitudes are typically considered the best predictors of behavior [73], we considered a simple questionnaire a sufficient instrument for the paper's goals. The common methods bias was controlled [74]. In particular, before sending the questionnaire to the respondents, it was tested on ten individuals via Zoom Cloud Meetings platform. We then performed a series of short semistructured interviews to verify whether individuals understood the questions correctly and to see if there was any systematic error or inconsistency in understanding the concepts operationalized by each question. No such error was detected.

Because of the COVID-19 pandemic, the survey was held online. The survey was delivered to respondents through social media channels and via email. Chain referral (snowball) sampling was employed due to the difficulty of procuring enough respondents for the survey during the lockdown $[75,76]$. One hundred questionnaires were distributed initially. Sixty-four individuals had answered within a week and agreed to propel the survey forward. The final number of respondents was assessed 30 days after the initial questionnaires were sent. Additionally, we assumed that the reduced set of questions (one for each hypothesis) would decrease the likelihood for the respondents to drop the survey midway or to answer randomly, as frequently happens when no incentive for completing an online survey is provided $[77,78]$. 
To eliminate any other potential source of bias, the broader scope of the survey was not revealed to the respondents before the debriefing, as we asked them to participate in "a very short survey about structural characteristics of jobs." The respondents that defined themselves as 'currently not working' were asked to answer the questions by thinking of their desired future job.

\subsection{Exploratory Analysis}

The heterogeneous Internet channels through which the survey was spread secured us good geographical coverage of respondents. Most respondents (53.9\%) were European. The dominant age group was between 18 and 30 years old (63.7\%). An almost equal number of males and females participated in the survey. The respondents age 18 and below were too few $(10.5 \%)$ to significantly influence the interpretation of the results. Therefore, this group was not considered during the formulation of the model.

Table 2 shows the distribution of answers of the respondents to the seven hypothesesrelated questions (in percentage terms).

Table 2. Survey results. Hypotheses-related questions.

\begin{tabular}{|c|c|c|c|c|}
\hline Questions & Yes & More Yes than No & More No than Yes & No \\
\hline $\begin{array}{c}\text { In your future or the current job, would you like to perform } \\
\text { less of the mundane activities (like replying to emails or } \\
\text { filling in forms)? }\end{array}$ & $32 \%$ & $30.8 \%$ & $22.8 \%$ & $14.5 \%$ \\
\hline $\begin{array}{l}\text { Would you like your future or the current employer to } \\
\text { provide you with more autonomy, control, and responsibility } \\
\text { for the tasks you are performing? }\end{array}$ & $51.7 \%$ & $36.6 \%$ & $5.5 \%$ & $6.2 \%$ \\
\hline $\begin{array}{c}\text { Currently or in the future, would you prefer to work in } \\
\text { larger work teams? }\end{array}$ & $27.1 \%$ & $18.5 \%$ & $35.4 \%$ & $19.1 \%$ \\
\hline $\begin{array}{l}\text { Would you like to work in an organization where your work } \\
\text { team is independent of the upper management and is } \\
\text { directly responsible for its own decisions and actions? }\end{array}$ & $49.5 \%$ & $34.2 \%$ & $10.5 \%$ & $5.8 \%$ \\
\hline $\begin{array}{l}\text { Would you like to work in an organization with fewer } \\
\text { bureaucratic levels between you and your manager? }\end{array}$ & $56.3 \%$ & $28.3 \%$ & $7.1 \%$ & $8.3 \%$ \\
\hline $\begin{array}{l}\text { Would you like to work in an organization with less formal } \\
\text { procedures, codes of behavior, practices, and rules? }\end{array}$ & $43.4 \%$ & $28.9 \%$ & $17.2 \%$ & $10.5 \%$ \\
\hline $\begin{array}{c}\text { Given the same wage, would you like to work fewer hours } \\
\text { on average? }\end{array}$ & $52.6 \%$ & $26.2 \%$ & $12.6 \%$ & $8.6 \%$ \\
\hline
\end{tabular}

Regarding the two organizational variables of the microlevel, job variety and job richness, we hypothesized that the adoption of artificial intelligence would eventually reduce the number of tasks, especially mundane ones, accompanied by greater job autonomy. While the increase in autonomy was well appreciated by the respondents, with more than $88 \%$ having either strongly ('yes') or weakly ('more yes than no') positive attitude towards richer jobs, the perspective of the reduced job variety, regardless of making it clear that the elimination would concern the most mundane of tasks, has encountered significant opposition, with only little more than $62 \%$ of respondents preferring, either strongly or weakly, the reduction in job variety. We consider this at least a bit concerning, as the reduction in job variety is one of the most direct and anticipated consequences of the increasing adoption of AI-driven technologies by companies.

The size of organizational units was the only variable we considered while investigating the horizontal axis of specialization of the mesolevel of organizational design. We hypothesized that the effect of the AI contingency on the variable was unclear because numerous other factors may influence the best fit. The hypothesized uncertainty in choosing the right size of organizational units was mirrored by respondents' preferences, with little more than $54 \%$ having either strongly or weakly positive attitudes toward larger 
work teams and the remaining part preferring to work in the smaller work teams. Thus, respondents showed no dominant preference for a particular size of organizational units.

All the other hypothesized organizational changes (decentralization, shorter organizational structures, organic organizational structures, and reduced working hours given the same wage) were positively evaluated by the predominant majority of the respondents.

Given the categorical nature of gathered data, multiple correspondence analysis was performed to investigate additional intersectional dynamics nested in the individuals' answers. Furthermore, it provided us with a statistical rationale upon which the model of the intraorganizational response to the AI contingency was based. Although MCA is unsuitable for inferential conclusions, we considered it the most appropriate tool for our goals. Indeed, the usage of multiple correspondence analysis and similar dimensionality reduction techniques (such as factor analysis) are common in both psychology and sociology to uncover existing stable taxonomies of traits [79] and tastes across social classes [68].

Six hypotheses-related categorical variables (scope, richness, decentralization, numb_of_ levels, organic, incentives) entered the analysis as active variables; the size of organizational units was not taken into consideration, as we were not able to formulate a coherent hypothesis concerning the best fit to the AI contingency in terms of the optimal dimension of organizational units. Consequently, the inclusion of the latter into MCA could have skewed the interpretation of the results. The analysis produced 18 uncorrelated dimensions. The first two accounted for $25.15 \%$ of the total inertia. As shown in Figure A1 (in Appendix A), these were the two dimensions that stood out.

Detailed examination of analytical results (Table 3) and MCA factor maps for both supplementary and active categories (Figures A2 and A3 in Appendix A) led us to the following observation: individuals with predominantly strongly negative attitudes towards the proposed changes were most likely to end up in the first quadrant of the plane (northwest); individuals with predominantly strongly positive attitudes were most likely to end up in the second quadrant (northeast); uncertain individuals with predominantly weakly positive attitudes were most likely to end up closer to the third quadrant (southwest); uncertain individuals with predominantly weakly negative attitudes towards proposed organizational changes were most likely to end up in the fourth quadrant of the plane (southeast).

The clustering tendency was further confirmed by MCA factor maps reporting the spatial distribution of 325 respondents along the two most significant dimensions according to their attitudes towards hypothesized organizational changes. As can be seen in Figures A4-A9 (in Appendix A), in all cases but two, confidence ellipses were relatively isolated, indicating the existence of a significant separation among the existing subgroups of respondents. Overall, individuals scoring higher on the first dimension were more likely to hold negative attitudes towards proposed organizational changes. Individuals scoring higher on the second dimension were more likely to give more firm answers ('yes' or 'no') to the questions. In accordance with MCA results, we may relabel the first dimension as 'overall negativity of attitudes' and the second dimension as 'overall level of certainty'.

Based on the MCA results, we devised four theoretical categories of attitude-holders: skeptics with strongly negative attitudes towards proposed organizational changes, uncertain skeptics with weakly negative attitudes towards proposed organizational changes, optimists with strongly positive attitudes towards proposed organizational changes, and doubtful optimists with weakly positive attitudes towards proposed organizational changes.

To understand the distribution of demographic characteristics on the plane, we analyzed the MCA results according to four supplementary variables (age, gender, status, student). As shown in Figures A10-A13 (in Appendix A), except for the working status, there was no significant overlap of confidence ellipses on the respective MCA factor maps (excluding the 'below 18 years old' category of age variable). Although when considered separately, variables denoting age, gender, and academic status (student/nonstudent) were not the best predictors of attitudinal strength, females in their twenties who were still studying were more likely to be uncertain about their attitudes. On the contrary, men 
in their thirties who had finished their studies held stronger attitudes on average. The negativity/positivity of attitudes and the demographic variables were almost uncorrelated.

Table 3. MCA active categories. Analytical results.

\begin{tabular}{|c|c|c|c|c|c|c|c|c|c|c|}
\hline Categories & Dim. 1 & Ctr.\% & $\operatorname{Cos}^{2}$ & v. Test & & Dim. 2 & Ctr.\% & $\operatorname{Cos}^{2}$ & $v$. Test & \\
\hline scope_More no than yes & 0.254 & 0.642 & 0.019 & 2.480 & * & -0.243 & 0.600 & 0.017 & -2.377 & 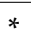 \\
\hline scope_More yes than no & 0.148 & 0.297 & 0.010 & 1.781 & & -0.603 & 4.982 & 0.162 & -7.236 & * \\
\hline scope_No & 0.917 & 5.332 & 0.142 & 6.789 & * & 0.569 & 2.082 & 0.055 & 4.208 & * \\
\hline scope_Yes & -0.738 & 7.633 & 0.256 & -9.110 & * & 0.496 & 3.504 & 0.116 & 6.123 & * \\
\hline richness_More no than yes & 1.198 & 3.483 & 0.084 & 5.222 & * & 0.272 & 0.183 & 0.004 & 1.186 & \\
\hline richness_More yes than no & 0.249 & 0.996 & 0.036 & 3.409 & * & -0.788 & 10.117 & 0.358 & -10.77 & * \\
\hline richness_No & 0.730 & 1.439 & 0.035 & 3.367 & * & 0.983 & 2.651 & 0.063 & 4.533 & * \\
\hline richness_Yes & -0.392 & 3.477 & 0.164 & -7.296 & * & 0.412 & 3.902 & 0.181 & 7.665 & * \\
\hline decentralization_More no than yes & 0.604 & 1.672 & 0.043 & 3.716 & * & -0.748 & 2.606 & 0.065 & -4.602 & * \\
\hline decentralization_More yes than no & -0.080 & 0.095 & 0.003 & -1.032 & & -0.720 & 7.891 & 0.269 & -9.337 & * \\
\hline decentralization_No & 2.207 & 12.482 & 0.303 & 9.901 & * & 0.909 & 2.152 & 0.051 & 4.078 & * \\
\hline decentralization_Yes & -0.333 & 2.410 & 0.109 & -5.942 & * & 0.547 & 6.607 & 0.294 & 9.759 & * \\
\hline numb_of_levels_More no than yes & 0.829 & 2.131 & 0.052 & 4.118 & * & -0.580 & 1.061 & 0.026 & -2.883 & * \\
\hline numb_of_levels_More yes than no & 0.169 & 0.352 & 0.011 & 1.906 & & -1.013 & 12.945 & 0.405 & -11.46 & * \\
\hline numb_of_levels_No & 2.157 & 16.937 & 0.422 & 11.687 & * & 1.016 & 3.819 & 0.094 & 5.504 & * \\
\hline numb_of_levels_Yes & -0.507 & 6.346 & 0.331 & -10.36 & * & 0.432 & 4.690 & 0.241 & 8.837 & * \\
\hline organic_More no than yes & 0.376 & 1.066 & 0.029 & 3.087 & * & -0.658 & 3.324 & 0.090 & -5.405 & * \\
\hline organic_More yes than no & -0.129 & 0.209 & 0.007 & -1.476 & & -0.701 & 6.328 & 0.200 & -8.048 & * \\
\hline organic_No & 1.678 & 12.910 & 0.329 & 10.325 & * & 1.048 & 5.114 & 0.128 & 6.445 & * \\
\hline organic_Yes & -0.468 & 4.168 & 0.168 & -7.378 & * & 0.476 & 4.379 & 0.174 & 7.501 & * \\
\hline incentives_More no than yes & 0.239 & 0.316 & 0.008 & 1.635 & & -0.333 & 0.624 & 0.016 & -2.279 & * \\
\hline incentives_More yes than no & 0.039 & 0.018 & 0.001 & 0.421 & & -0.607 & 4.293 & 0.131 & -6.503 & * \\
\hline incentives_No & 1.811 & 12.376 & 0.309 & 10.007 & * & 1.176 & 5.308 & 0.130 & 6.500 & * \\
\hline incentives_Yes & -0.373 & 3.214 & 0.155 & -7.082 & * & 0.189 & 0.838 & 0.040 & 3.586 & * \\
\hline
\end{tabular}

dim. 1 and dim. 2 are the coordinates of categories on the plane, ctr. is the contribution of a category to the definition of dimensions (in percentage terms), $\cos ^{2}$ is the quality of representation of each category on the factor map, $v$. test is a test statistic. Only categories with * have coordinates significantly different from zero ( $p$-value less or equal to 0.05$)$.

\section{Formalization of the Model and Discussion}

The respondents' attitudes showed a considerable degree of concordance with the hypothesized organizational changes. For all the proposed changes but two, a predominant majority of respondents answered either 'yes' or 'more yes than no'. Table 4 summarizes survey results in more descriptive terms. We purposefully relabeled the answers as in favor', 'slightly in favor' (for 'yes' and 'more yes than no' categories) and 'in disfavor', 'slightly in disfavor' (for 'no' and 'more no than yes' categories) for the sake of better presentational clarity. Labels used in the 'Levels of concordance' column are also arbitrary. Once again, we used them only to enhance the presentational clarity of the results. We considered overall explicit attitudes to be concordant with the hypothesized organizational change if the majority of respondents had been either 'in favor' or 'slightly in favor' of the proposed change. 
Table 4. Summary of survey results.

\begin{tabular}{|c|c|c|c|}
\hline Organizational Variable & $\begin{array}{l}\text { The Best Fit to AI Contingency } \\
\text { (in Terms of the Degree of org. } \\
\text { Variable) }\end{array}$ & Survey Results & $\begin{array}{l}\text { Level of Concordance between } \\
\text { Overall Explicit Attitudes and } \\
\text { the Hypothesized Best Fit }\end{array}$ \\
\hline Variety/scope of job & Low (less of the mundane tasks) & $\begin{array}{l}\text { In favor: } 32 \% \text {. Slightly in favor: } \\
30.8 \% \text {. Slightly in disfavor: } 22.8 \% \text {. } \\
\text { In disfavor: } 14.5 \%\end{array}$ & Moderate $>60 \%$ \\
\hline Richness/autonomy of job & High & $\begin{array}{l}\text { In favor: } 51.7 \% \text {. Slightly in favor: } \\
36.6 \% \text {. Slightly in disfavor: } 5.5 \% \text {. } \\
\text { In disfavor: } 6.2 \%\end{array}$ & Strong $>80 \%$ \\
\hline $\begin{array}{l}\text { Span of control (size of } \\
\text { organizational units) }\end{array}$ & The effect of AI is unclear & $\begin{array}{l}\text { In favor of larger teams: } 27.1 \% \text {. } \\
\text { Slightly in favor of larger teams: } \\
18.5 \% \text {. In favor of smaller teams: } \\
19.1 \% \text {. Slightly in favor of smaller } \\
\text { teams: } 35.4 \%\end{array}$ & $\begin{array}{l}\text { Overall slight preference towards } \\
\text { smaller work teams }>50 \%\end{array}$ \\
\hline Degree of centralization & Low & $\begin{array}{l}\text { In favor: } 49.5 \% \text {. Slightly in favor: } \\
34.2 \% \text {. Slightly in disfavor: } 10.5 \% \text {. } \\
\text { In disfavor: } 5.8 \%\end{array}$ & Strong $>80 \%$ \\
\hline $\begin{array}{l}\text { Number of hierarchical levels } \\
\text { (length of the chain of command) }\end{array}$ & Low & $\begin{array}{l}\text { In favor: } 56.3 \% \text {. Slightly in favor: } \\
28.3 \% \text {. Slightly in disfavor: } 7.1 \% \text {. } \\
\text { In disfavor: } 8.3 \%\end{array}$ & Strong $>80 \%$ \\
\hline Standardization and formalization & Low (organic structure) & $\begin{array}{l}\text { In favor: } 43.4 \% \text {. Slightly in favor: } \\
28.9 \% \text {. Slightly in disfavor: } 17.2 \% \text {. } \\
\text { In disfavor: } 10.5 \%\end{array}$ & Moderately strong $>70 \%$ \\
\hline Incentives & $\begin{array}{l}\text { High (fewer working hours on } \\
\text { average given the same wage) }\end{array}$ & $\begin{array}{l}\text { In favor: } 52.6 \% \text {. Slightly in favor: } \\
26.2 \% \text {. Slightly in disfavor: } 12.6 \% \text {. } \\
\text { In disfavor: } 8.6 \%\end{array}$ & Strong $>80 \%$ \\
\hline
\end{tabular}

The survey provided solid evidence that the hypothesized organizational changes will encounter little to no organizational resistance from employees. Nevertheless, one organizational variable appears to be more critical than the others. While most of the respondents $(62.8 \%)$ preferred less job variety by renouncing the most mundane tasks, a significant part of the respondents was still not willing to accept jobs with a smaller scope. Promoters of organizational change should consider this while implementing the AI-driven changes related to the horizontal dimension of the micro-organizational structure.

As for the MCA results, we considered the age group between 18 and 30 years old to be especially interesting, mainly for a sociological reason. Sociologists typically label those young people in the developed countries as 'emergent adults' [80]. They are closely related to a novel cohort of 'cultural intermediaries', first noticed by Bourdieu [51] and later described by Featherstone [81]. As the result of the major erosion of traditional values, higher demand for education on the job market, financial liberation of females, and other related reasons, those young males and females seek to postpone their marriage until their 30 s and actively engage in what Featherstone calls an "aestheticization of everyday life" marked by experiential consumption, extensive traveling, and prolonged education to accumulate cultural capital needed later in life [51]. The category of cultural intermediaries is important here for mainly two reasons. Firstly, they typically are the early adopters of technology, fashions, ideas, and lifestyles. Secondly, they usually transmit those attitudes and trends to a broader population through various communication channels [81]. This alone makes them the ultimate trendsetters and influencers [82].

While most cultural intermediaries, as described by Featherstone [81] and Stillerman [51], are emergent adults, it is essential to emphasize that not all emergent adults fall within the category of cultural intermediaries.

The MCA revealed the theoretical existence of four groups of individuals: optimists with strongly positive attitudes towards hypothesized changes, skeptics with strongly negative attitudes towards hypothesized changes, and two other groups showing higher degrees of uncertainty in terms of their attitudes (either predominantly positive or negative). 
While the group of optimists is significant, it is the group of doubtful optimists that requires significant managerial attention for mainly two reasons:

- Individuals within the group hold weaker positive attitudes towards the imminent organizational changes, and therefore their attitudes may easily become negative in the future.

- Gender aside, other relevant demographic characteristics of the group (age and academic status) fit the description of cultural intermediaries given by Featherstone [81]. Therefore, individuals belonging to the group are more likely to change the attitudes of others, and they are the most influential trendsetters and early adopters.

Optimists and doubtful optimists constituted a predominant majority of the respondents. While little managerial effort is advised regarding the former, we consider the latter to be the most significant of the four theoretical groups. We suggest that promoters of organizational change make considerable efforts to convince members of this group about the benefits of the upcoming AI-driven organizational changes. By doing so, not only may they strengthen the already positive attitudes of cultural intermediaries that constitute the core of the group, but it may be possible to leverage those individuals' position as idea brokers to convince the other doubtful individuals (skeptics and optimists) about positive aspects of the upcoming changes. According to the model, a significantly lower number of skeptics with strong negative attitudes is not worth the managerial time and effort, as it is more likely that they will continue to pose a significant resistance to the upcoming organizational changes no matter what types of communication and change implementation strategies will be adopted.

Based on the results of MCA, a simple $2 \times 2$ matrix was created. We designed it to provide the promoters of organizational change with a simple tool to make their change implementation strategies more efficient. The rows of the matrix denote the strength of attitudes (weak or strong). In contrast, the columns denote the type of attitudes (positive or negative) towards organizational changes caused by the AI contingency (Table 5).

Table 5. Model of intraorganizational response to the AI contingency.

\begin{tabular}{|c|c|c|}
\hline & Positive Attitudes & Negative Attitudes \\
\hline Strong attitudes & $\begin{array}{l}\text { II Optimists } \\
\text { The most stable cohort posing no threat in terms of } \\
\text { organizational resistance to changes. MCA maps } \\
\text { them as men mostly over } 30 \text { years old who have } \\
\text { finished their education. Given the strength of } \\
\text { their attitudes, no managerial efforts are } \\
\text { recommended. }\end{array}$ & $\begin{array}{l}\text { I Skeptics } \\
\text { The most problematic group of individuals posing } \\
\text { a significant resistance to the upcoming } \\
\text { organizational changes. They are, however, } \\
\text { significantly outnumbered by individuals } \\
\text { belonging to other groups. Managerial efforts to } \\
\text { convince them of the positive aspects of changes } \\
\text { may be too expensive and ineffective; therefore, no } \\
\text { action in their regard is recommended. }\end{array}$ \\
\hline Weak attitudes & $\begin{array}{l}\text { III Doubtful optimists } \\
\text { The positive attitudes of this group's members are } \\
\text { weak; managers should implement proactive } \\
\text { strategies to make those attitudes more stable. } \\
\text { MCA maps the individuals belonging to the group } \\
\text { as primarily female, under } 30 \text { years old, and still } \\
\text { studying. The latter two characteristics fit the } \\
\text { profile of cultural intermediaries. This subgroup is } \\
\text { highly capable of influencing the attitudes of their } \\
\text { own and other groups' members. }\end{array}$ & $\begin{array}{l}\text { IV Doubtful skeptics } \\
\text { Although their attitudes are negative, those } \\
\text { individuals remain quite unsure about them. No } \\
\text { particular action is recommended, as addressing } \\
\text { cultural intermediaries (in group III) more } \\
\text { effectively may be the best strategy to convince } \\
\text { doubtful skeptics about the positive aspects of } \\
\text { organizational changes indirectly. }\end{array}$ \\
\hline
\end{tabular}

As shown in Table 5, the promoters of change should invest most of their efforts to win the predisposition of cultural intermediaries. Losing their favor may be detrimental for the whole process of change, as their negative attitudes may spill over into other groups, which in turn may cause significant organizational inertia and resistance to change. 


\section{Conclusions}

\subsection{Main Findings}

Artificial intelligence is becoming one of the most relevant technological and environmental contingencies of the near future [83,84]. According to the core notions of contingency theories, we consider organizational fit with AI strategically important for any company to gain and maintain a sustainable competitive advantage. Analysis of existing academic literature on the topic led us to formulate a set of hypotheses concerning the potential changes that further development and the adoption of AI by companies may bring to their internal organizational structures, on both micro and meso levels of analysis.

The major changes involve the micro-organizational level and primarily concern job variety and job richness. Although a substantial part of related literature points to the probable reduction in job variety, in terms of mostly eliminating mundane tasks out of jobs, employees will also see their jobs becoming richer in terms of greater procedural autonomy and accountability for the performed tasks. Significant changes regarding mesoorganizational variables include reduction in the degree of centralization, the passage from tall to flat organizational structures, the increasing adoption of organic organizational structures, and the decrease in the average number of working hours per week as the main nonmonetary incentive. While most of those changes reflect the major modern-day organizational trends, artificial intelligence may significantly increase the speed of their adoption. Still, we are entirely aware that only further systematic research efforts within the area may prove us right or wrong.

Regardless of organizational changes related to the further adoption of AI, the anthropic aspects of any organization should remain the primary concern. In light of the latter consideration, it was deemed important to understand if any of the hypothesized changes will encounter some form of organizational resistance or inertia. The crosscultural survey of 325 current and future employees of all ages showed a satisfactory degree of match between hypothesized organizational changes and explicit personal attitudes of individuals towards them. The reduction in job variety, however, even if by means of eliminating the more mundane tasks out of jobs, was seen as a negative trend by a consistent minority of the respondents. Therefore, managers are advised to be particularly careful in redesigning the horizontal dimension of jobs in relation to the AI contingency.

By considering the explicit attitudes that individuals crossculturally hold regarding the hypothesized organizational changes and relying on the results of multiple correspondence analysis, the model of intraorganizational response to the AI contingency was developed. The model theorizes the existence of four categories of jobholders: optimists, doubtful optimists, skeptics, and doubtful skeptics. We consider the latter group to be the most important due to the 'cultural intermediaries' cohort it incorporates. This alone makes individuals belonging to the group highly capable of influencing the attitudes of their own and other groups' members.

Although several attempts were made to understand the nature of the interrelationship between AI-related technologies and the structural characteristics of an organization [20$22,30,39,40,46]$, to our knowledge, this study represents the first in its kind addressing the issue systemically across multiple dimensions of the ideal-type of a typical organizational structure. Indeed, the previous studies were mainly concerned with micro job-related issues, both vertically $[20-23,25,26]$ and horizontally $[29,31,32]$. The important mesolevel variables - mainly related to the span of control, number of hierarchical levels, centralization, standardization, formalization, and incentives-have been consistently neglected by scholars. Indeed, to hypothesize plausible organizational changes in response to the AI contingency on the meso level of analysis, we have extensively relied on a more general ontological framework concerning the role of IT within organizations [43]. Those considerations have been integrated with famous sociological theories regarding the state of modernity and risk society $[50,52,53]$. Compared to other studies in the field, ours offers a unified and multidisciplinary perspective on the topic. Thus, it represents an integrative effort to bridge agency and structure on both micro and meso levels of analysis. 


\subsection{Managerial Implications}

The present study is potentially valuable for the promoters of organizational change, regardless of their formal role within an organization. Indeed, more and more researchers, both in industry and academia, recognize AI as a potentially disruptive technology representing a paradigm shift similar in magnitude to the discovery of the silicon transistor. Given such importance, artificial intelligence could potentially become the most critical technological contingency for most organizations. The main question for us was not whether such substantial changes happen, but rather, if they happen, what the organizational consequences will be, and what are the best ways to implement them in a relatively efficient manner while considering the resisting forces of agents (mainly employees) on the structure. In particular, our model suggests a clear line of action-in terms of which actors should be targeted first and foremost-for the promoters of organizational changes. The latter can use the model to successfully enable the AI-related organizational changes, especially when some employees meet such changes with a high degree of suspicion.

\subsection{Theoretical Implications}

Regardless of what the future will bring, we firmly believe the human aspect should always be given primacy within organizational studies. However, as already mentioned, most scholars have investigated the topic either from the more technical or purely generalist perspective concerning the elaboration of information and decision making. In the current scenario, our study taps into the research gap and was novel from at least two points of view: it adopted a structural approach and studied the influence of AI on single organizational variables and-more importantly-it recognized the primacy of individuals in the workplace. Indeed, the latter are not just passively internalizing and adapting to the changes but are in a continuous negotiation process with the promoters of organizational change. By putting the individual first, we hope to inspire and contribute to the future line of research, adopting the perspectives of psychological and sociological evaluation of the AI phenomenon in the workplace.

\subsection{Research Limitations and Further Research Directions}

Irrespective of strong conclusions, the model of intraorganizational response to the AI contingency requires further empirical validation and testing. Firstly, while some of the hypothesized changes of organizational variables are undoubtedly linked to AI-such as the reduction in job variety-others are part of more general organizational trends, or the extent to which artificial intelligence will contribute to those changes is unclear. Organizational literature dealing with the influence of AI on the important variables of the intraorganizational structure is still very poor. Only additional research may further confirm or refute the proposed set of hypotheses. Secondly, the performed analysis of individuals' attitudes was based on a relatively small sample of respondents. Furthermore, chain referral sampling was used, mainly due to the ongoing COVID-19 pandemic. The sampling method was contingent on the lockdown situation; however, we do recognize that the representativeness of the sample could have been affected as a result [76]. Further replication studies with higher numbers of participants and more stringent sampling requirements are needed to confirm the obtained results.

Nevertheless, we remain confident about the practical relevance our model may confer to organizational change practitioners, especially now, in light of the upcoming technological and societal changes caused by the increasing development and adoption of intelligent software and hardware. We also believe that the methodology used in the research has the merit of generalizability. Thus, it may be applied to different kinds of contingencies. Moreover, the research outcomes are unique. Indeed, for the first time (within the specific domain of AI in organizational studies), the emphasis was put on individual agents, as implementors of change and jobholders, rather than on the technology or the overall structure. We hope our paper will provide researchers with helpful hints and insights regarding both methodology and the distinctive ontological perspective. 
Author Contributions: Conceptualization, F.B. and I.R.; methodology, I.R. and A.B.B.; software, I.R.; validation, F.B. and A.B.B., formal analysis, I.R. and A.B.B.; resources, I.R.; data curation, A.B.B.; writing-original draft preparation, I.R. and A.B.B.; writing-review and editing, F.B.; visualization, I.R. and A.B.B.; supervision, F.B.; project administration, F.B.; All authors have read and agreed to the published version of the manuscript.

Funding: This research received no external funding.

Institutional Review Board Statement: Not applicable.

Informed Consent Statement: Informed consent was obtained from all subjects involved in the study.

Data Availability Statement: The dataset and the R Code are provided on request from the authors.

Conflicts of Interest: The authors declare no conflict of interest.

\section{Appendix A}

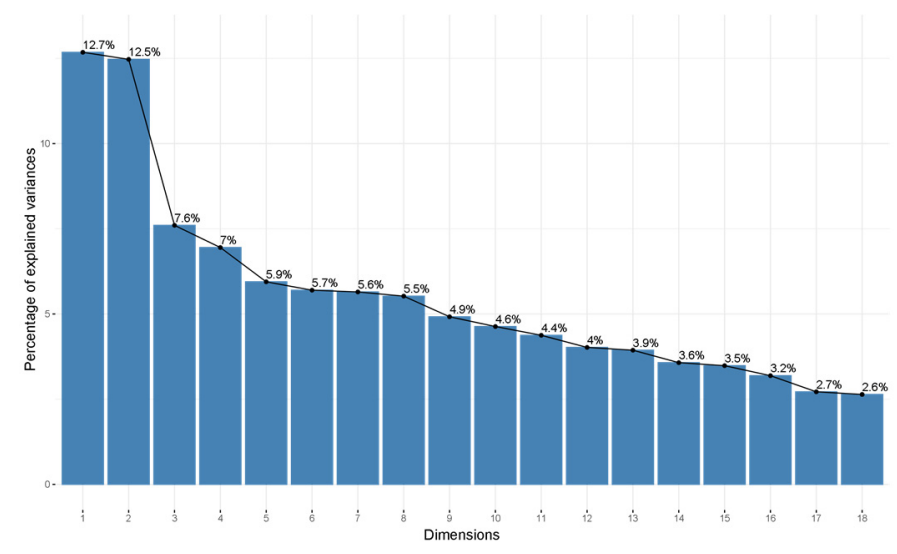

Figure A1. MCA. Decomposition of total inertia.

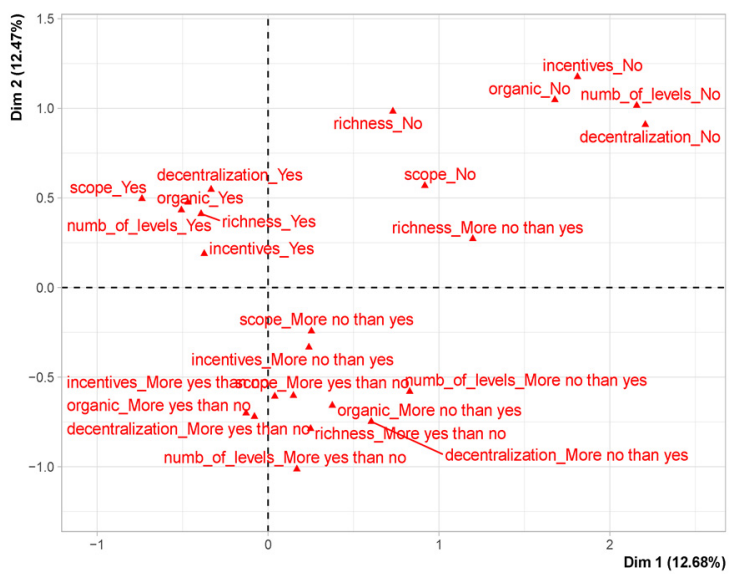

Figure A2. MCA. Active categories. 




Figure A3. MCA. Supplementary categories.

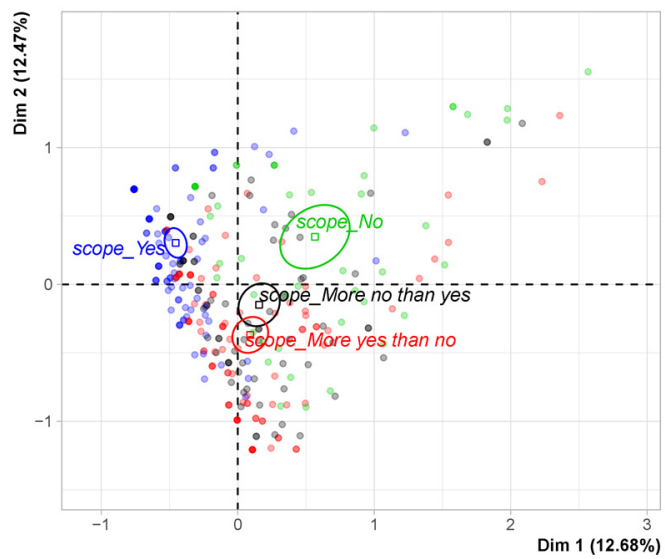

Figure A4. MCA. Distribution of respondents by attitudes towards reduced job scope.

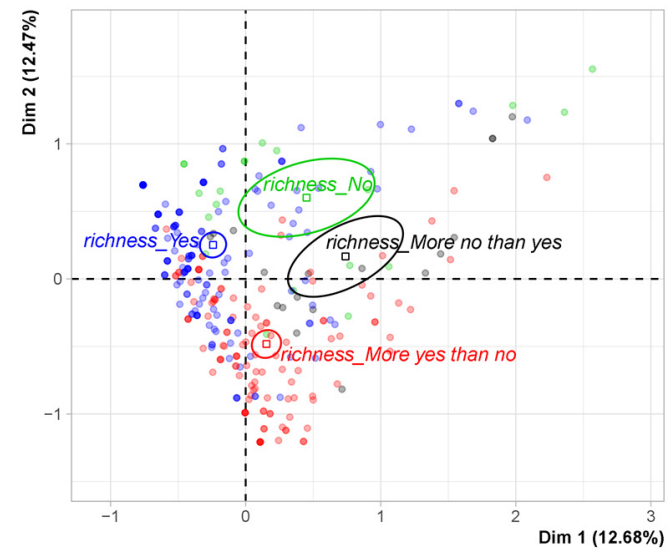

Figure A5. MCA. Distribution of respondents by attitudes towards increased job richness. 


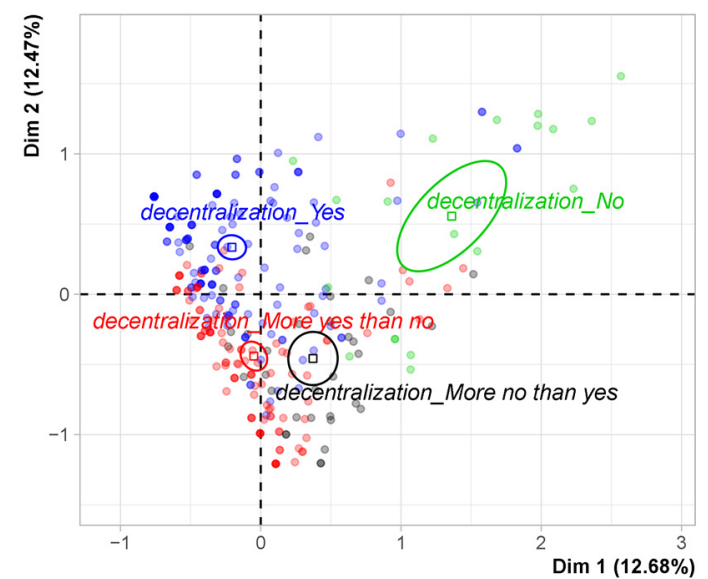

Figure A6. MCA. Distribution of respondents by attitudes towards increased decentralization.

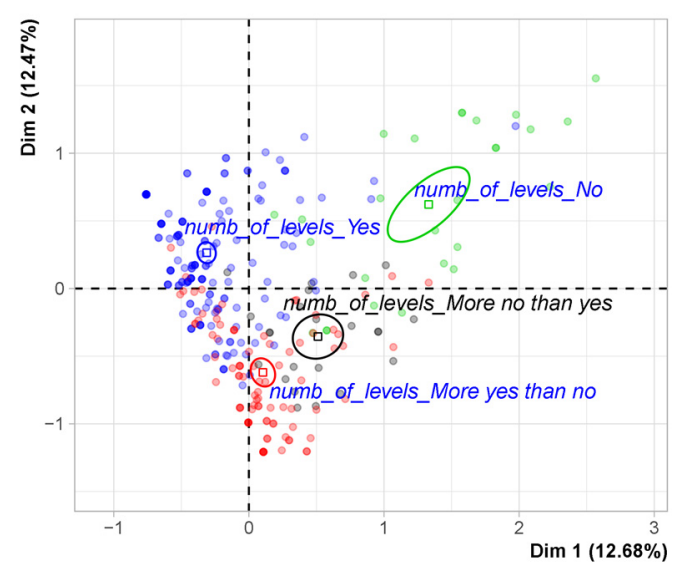

Figure A7. MCA. Distribution of respondents by attitudes towards flatter organizational structures.

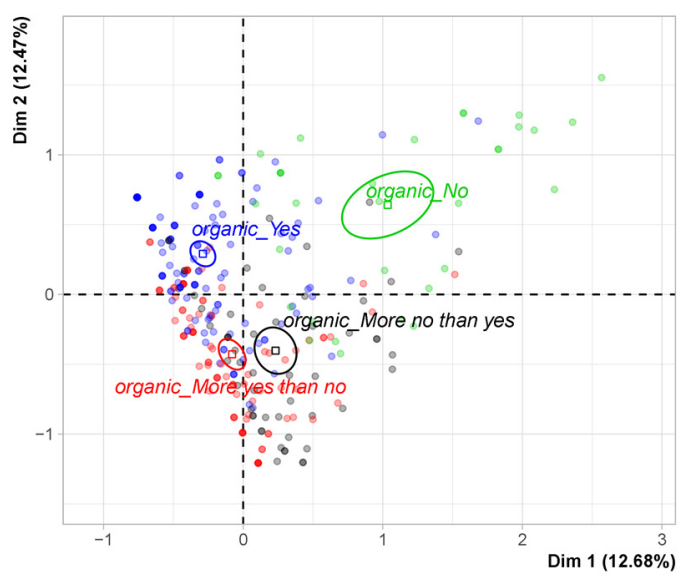

Figure A8. MCA. Distribution of respondents by attitudes towards organic structures. 


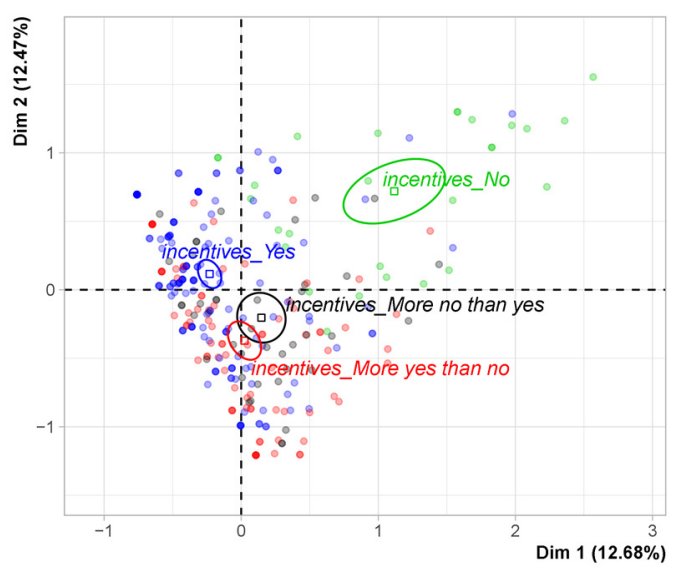

Figure A9. MCA. Distribution of respondents by attitudes towards reduced working hours.



Figure A10. MCA. Distribution of respondents by age.

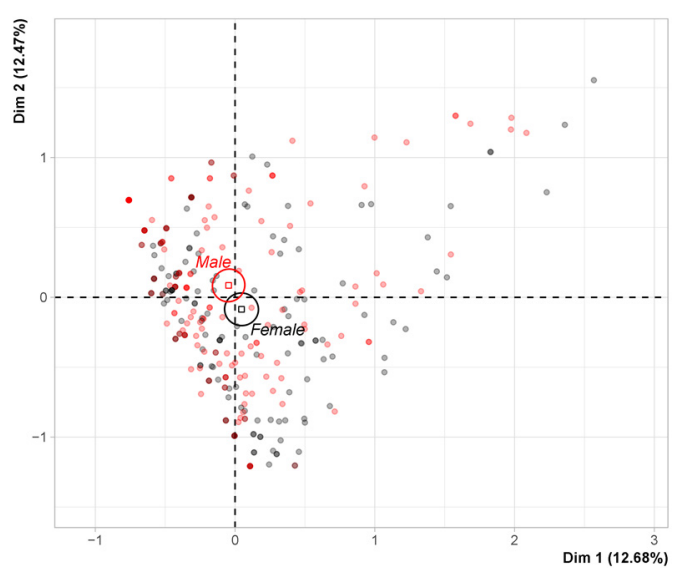

Figure A11. MCA. Distribution of respondents by gender. 


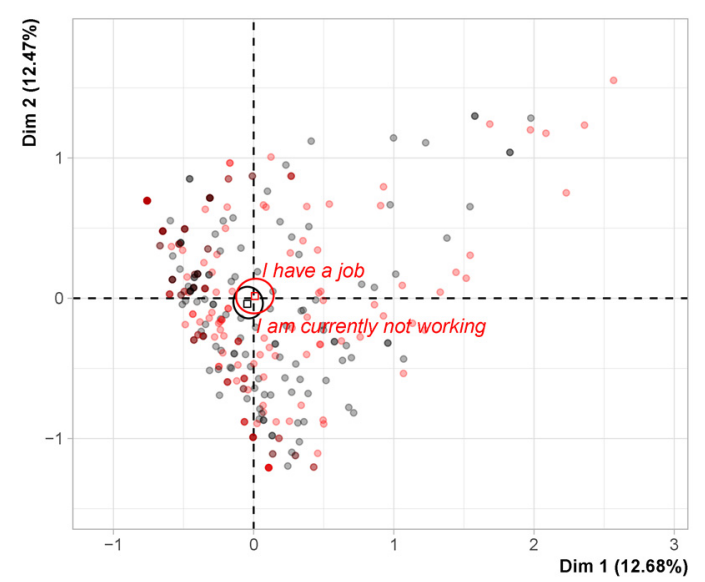

Figure A12. MCA. Distribution of respondents by working status.

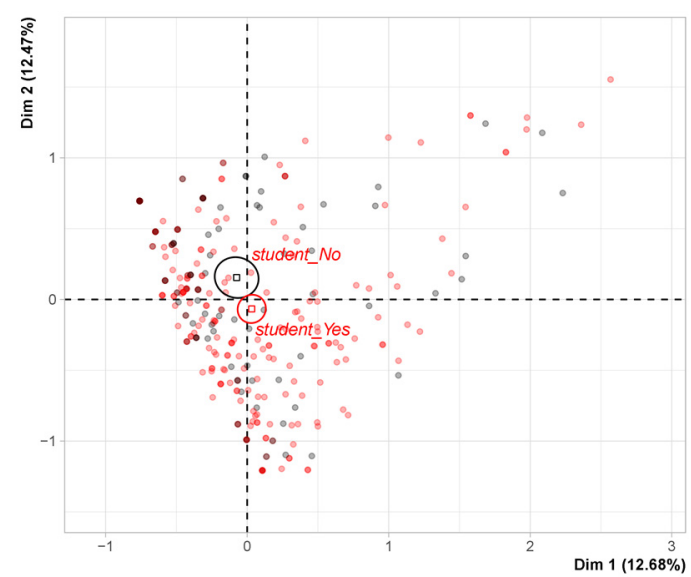

Figure A13. MCA. Distribution of respondents by academic status.

\section{References}

1. Kranzberg, M. The Information Age: Evolution or Revolution? In Information Technologies and Social Transformation; National Academy Press: Washington, DC, USA, 1985.

2. Makridakis, S. The Forthcoming Artificial Intelligence (AI) Revolution: Its Impact on Society and Firms. Futures 2017, 90, 46-60. [CrossRef]

3. Paschen, U.; Pitt, C.; Kietzmann, J. Artificial Intelligence: Building Blocks and an Innovation Typology. Bus. Horiz. 2020, 63, 147-155. [CrossRef]

4. Vaishya, R.; Javaid, M.; Khan, I.H.; Haleem, A. Artificial Intelligence (AI) Applications for COVID-19 Pandemic. Diabetes Metab. Syndr. Clin. Res. Rev. 2020, 14, 337-339. [CrossRef] [PubMed]

5. Akhtar, M.; Kraemer, M.U.G.; Gardner, L.M. A Dynamic Neural Network Model for Predicting Risk of Zika in Real Time. BMC Med. 2019, 17, 171. [CrossRef]

6. Bashirpour Bonab, A.; Rudko, I.; Bellini, F. A Review and a Proposal about Socio-Economic Impacts of Artificial Intelligence. In Business Revolution in a Digital Era; Springer Proceedings in Business and Economics; Dima, A.M., D'Ascenzo, F., Eds.; Springer: Cham, Switzerland, 2021; pp. 251-270.

7. Lula, P.; Dospinescu, O.; Homocianu, D.; Sireteanu, N.-A. An Advanced Analysis of Cloud Computing Concepts Based on the Computer Science Ontology. Comput. Mater. Contin. 2021, 66, 2425-2443. [CrossRef]

8. Emmert-Streib, F.; Yli-Harja, O.; Dehmer, M. A Clarification of Misconceptions, Myths and Desired Status of Artificial Intelligence. arXiv 2020, 3, 1-7. [CrossRef]

9. Dirican, C. The Impacts of Robotics, Artificial Intelligence on Business and Economics. Procedia Soc. Behav. Sci. 2015, 195, 564-573. [CrossRef]

10. Brynjolfsson, E.; McAfee, A. The Business of Artificial Intelligence. Harv. Bus. Rev. 2017.

11. Lee, S.; Shi, Q.; Lee, C. From Flexible Electronics Technology in the Era of IoT and Artificial Intelligence toward Future Implanted Body Sensor Networks. APL Mater. 2019, 7, 031302. [CrossRef]

12. Donaldson, L. The Contingency Theory of Organizations; SAGE Publications: Thousand Oaks, CA, USA, 2001; ISBN 978-0-76191574-4. 
13. Ginsberg, A.; Venkatraman, N. Contingency Perspectives of Organizational Strategy: A Critical Review of the Empirical Research. Acad. Manag. Rev. 1985, 10, 421-434. [CrossRef]

14. Isotta, F. La Progettazione Organizzativa; CEDAM: Padova, Italy, 2011; ISBN 978-88-13-31748-5.

15. Steiner, A.; Jack, S.; Farmer, J.; Steinerowska-Streb, I. Are They Really a New Species? Exploring the Emergence of Social Entrepreneurs through Giddens' Structuration Theory. Bus. Soc. 2021.

16. Daugherty, P.; Purdy, M. Why Artificial Intelligence Is a Future of Growth? Accenture 2017. Available online: https://dl.icdst.org/ pdfs / files2/2aea5d87070f0116f8aaa9f545530e47.pdf (accessed on 22 August 2017).

17. Hendler, J. Intelligent Agents: Where AI Meets Information Technology. IEEE Expert 1996, 11, 20-23. [CrossRef]

18. Fleming, P. Robots and Organization Studies: Why Robots Might Not Want to Steal Your Job. Organ. Stud. 2019, 40, 23-38. [CrossRef]

19. Grace, K.; Salvatier, J.; Dafoe, A.; Zhang, B.; Evans, O. Viewpoint: When Will AI Exceed Human Performance? Evidence from AI Experts. J. Artif. Intell. Res. 2018, 62, 729-754. [CrossRef]

20. Su, Z.; Togay, G.; Côté, A.-M. Artificial Intelligence: A Destructive and yet Creative Force in the Skilled Labour Market. Hum. Resour. Dev. Int. 2021, 24, 341-352. [CrossRef]

21. Johnson, M.; Jain, R.; Brennan-Tonetta, P.; Swartz, E.; Silver, D.; Paolini, J.; Mamonov, S.; Hill, C. Impact of Big Data and Artificial Intelligence on Industry: Developing a Workforce Roadmap for a Data Driven Economy. Glob. J. Flex. Syst. Manag. 2021, 22, 197-217. [CrossRef]

22. Alekseeva, L.; Azar, J.; Giné, M.; Samila, S.; Taska, B. The Demand for AI Skills in the Labor Market. Labour Econ. $2021,71$. [CrossRef]

23. Volini, E.; Schwartz, J.; Denny, B.; Mallon, D.; von Durme, Y.; Hauptmann, M.; Yan, R.; Poynton, S. 2020 Deloitte Global Human Capital Trends; Deloitte Report; Deloitte: Shanghai, China, 2020.

24. Volini, E.; Occean, P.; Stephan, M.; Walsh, B. 2017 Deloitte Global Human Capital Trends; Deloitte Report; Deloitte: Shanghai, China, 2017.

25. Sampson, S.E. A Strategic Framework for Task Automation in Professional Services. J. Serv. Res. 2021, 24, 122-140. [CrossRef]

26. Brynjolfsson, E.; Mitchell, T.; Rock, D. What Can Machines Learn, and What Does It Mean for Occupations and the Economy? AEA Pap. Proc. 2018, 108, 43-47. [CrossRef]

27. McKendrick, J. Artificial Intelligence Will Replace Tasks, Not Jobs. Available online: https://www.forbes.com/sites/ joemckendrick/2018/08/14/artificial-intelligence-will-replace-tasks-not-jobs/ (accessed on 20 April 2021).

28. Dospinescu, O.; Ilinca, L. The Recognition of Fingerprints on Mobile Applications-An Android Case Study. J. East. Eur. Res. Bus. Econ. 2016, 2016, 1-11. [CrossRef]

29. Jaiswal, A.; Arun, C.J.; Varma, A. Rebooting Employees: Upskilling for Artificial Intelligence in Multinational Corporations. Int. J. Hum. Resour. Manag. 2021. [CrossRef]

30. Wisskirchen, G.; Biacabe, B.T.; Bormann, U.; Muntz, A.; Niehaus, G.; Soler, G.J.; von Brauchitsch, B. Artificial Intelligence and Robotics and Their Impact on the Workplace; IBA Global Employment Institute: London, UK, 2017.

31. Tokarz, A.; Malinowska, D. From Psychological Theoretical Assumptions to New Research Perspectives in Sustainability and Sustainable Development: Motivation in the Workplace. Sustainability 2019, 11, 2222. [CrossRef]

32. Malik, N.; Tripathi, S.N.; Kar, A.K.; Gupta, S. Impact of Artificial Intelligence on Employees Working in Industry 4.0 Led Organizations. Int. J. Manpow. 2021. [CrossRef]

33. Azeez, S. A Critical Review of Impact of Job Enrichment and Employee Performance, Motivation and Productivity. Int. J. Sci. Res. Eng. Dev. 2020, 3, 9.

34. Galbraith, J.R. Designing Organizations: Strategy, Structure, and Process. at the Business Unit and Enterprise Levels; John Wiley \& Sons: Hoboken, NJ, USA, 2014; ISBN 978-1-118-40995-4.

35. Hill, S.; Martin, R.; Harris, M. Decentralization, Integration and the Post-Bureaucratic Organization: The Case of R\&d. J. Manag. Stud. 2000, 37, 563-586. [CrossRef]

36. Čudanov, M.; Jaško, O.; Jevtić, M. Influence of Information and Communication Technologies on Decentralization of Organizational Structure. Comput. Sci. Inf. Syst. 2009, 6, 93-109. [CrossRef]

37. Hempel, P.S.; Zhang, Z.-X.; Han, Y. Team Empowerment and the Organizational Context: Decentralization and the Contrasting Effects of Formalization. J. Manag. 2012, 38, 475-501. [CrossRef]

38. Levine, D.I. Automation as Part of the Solution. J. Manag. Inq. 2019, 28, 316-318. [CrossRef]

39. Malone, T.W. Is "Empowerment” Just a Fad? Control, Decision-Making, and Information Technology. BT Technol. J. 1999, 17, 141-144. [CrossRef]

40. Mohanty, S.; Vyas, S. Decentralized Autonomous Organizations = Blockchain + AI + IoT. In How to Compete in the Age of Artificial Intelligence: Implementing a Collaborative Human-Machine Strategy for Your Business; Mohanty, S., Vyas, S., Eds.; Apress: Berkeley, CA, USA, 2018; pp. 189-206, ISBN 978-1-4842-3808-0.

41. DuBrin, A.J. Fundamentals of Organizational Behavior: An Applied Perspective; Elsevier: Amsterdam, The Netherlands, 2013; ISBN 978-1-4831-4817-5.

42. Rajan, R.G.; Wulf, J. The Flattening Firm: Evidence from Panel Data on the Changing Nature of Corporate Hierarchies. Rev. Econ. Stat. 2006, 88, 759-773. [CrossRef]

43. Lawler, E.E. Substitutes for Hierarchy. Organ. Dyn. 1988, 17, 5-15. [CrossRef] 
44. King, B.A.; Hammond, T.; Harrington, J. Disruptive Technology: Economic Consequences of Artificial Intelligence and the Robotics Revolution. J. Strat. Innov. Sustain. 2017, 12, 53-67. [CrossRef]

45. Müller, V.C.; Bostrom, N. Future Progress in Artificial Intelligence: A Survey of Expert Opinion. In Fundamental Issues of Artificial Intelligence; Müller, V.C., Ed.; Synthese Library; Springer: Cham, Switzerland, 2016; pp. 555-572, ISBN 978-3-319-26485-1.

46. Fountaine, T.; McCarthy, B.; Saleh, T. Building the AI-Powered Organization. Harv. Bus. Rev. 2019, 97, 62-73.

47. Schilling, M.A. Strategic Management of Technological Innovation, 6th ed.; McGraw-Hill Education: New York, NY, USA, 2016; ISBN 978-93-5316-846-9.

48. Kanten, P.; Kanten, S.; Gurlek, M. The Effects of Organizational Structures and Learning Organization on Job Embeddedness and Individual Adaptive Performance. Procedia Econ. Financ. 2015, 23, 1358-1366. [CrossRef]

49. Powell, T.C. Organizational Alignment as Competitive Advantage. Strat. Manag. J. 1992, 13, 119-134. [CrossRef]

50. Bauman, Z.; Haugaard, M. Liquid Modernity and Power: A Dialogue with Zygmunt Bauman. J. Power 2008, 1, 111-130. [CrossRef]

51. Stillerman, J. The Sociology of Consumption: A Global Approach; John Wiley \& Son: Hoboken, NJ, USA, 2015; ISBN 978-0-7456-9691-1.

52. Bauman, Z. Liquid Modernity; John Wiley \& Sons: Hoboken, NJ, USA, 2013; ISBN 978-0-7456-5701-1.

53. Leiss, W.; Beck, U.; Ritter, M.; Lash, S.; Wynne, B. Risk Society, Towards a New Modernity. Can. J. Sociol. Cah. Can. Sociol. 1995, 19, 544. [CrossRef]

54. Burns, T.; Stalker, G.M. Mechanistic and Organic Systems of Management. In Sociology of Organizations: Structures and Relationships; SAGE Publications: Thousand Oaks, CA, USA, 2011; ISBN 978-1-4129-9196-4.

55. Burns, T.; Stalker, G.M. The Management of Innovation; Tavistock Publishing: London, UK, 2016.

56. Puaschunder, J.M. Artificial Intelligence Market Disruption. In Proceedings of the International RAIS Conference on Social Sciences and Humanities, Rockville, MD, USA, 10-11 June 2019; pp. 1-8.

57. Bonner, S.E.; Sprinkle, G.B. The Effects of Monetary Incentives on Effort and Task Performance: Theories, Evidence, and a Framework for Research. Acc. Organ. Soc. 2002, 27, 303-345. [CrossRef]

58. Ponta, L.; Delfino, F.; Cainarca, G.C. The Role of Monetary Incentives: Bonus and/or Stimulus. Adm. Sci. 2020, 10, 8. [CrossRef]

59. Abdullah, A.A.; Wan, H.L. Relationships of Non-Monetary Incentives, Job Satisfaction and Employee Job Performance. Int. Rev. Manag. Bus. Res. 2013, 2, 1085-1091.

60. Hicks, V.; Adams, O. Pay and Non-pay Incentives, Performance and Motivation. In Studies in HSOEP; ITGPress: Antwerp, Belgium, 2003; p. 18.

61. Bell, L.A.; Freeman, R.B. The Incentive for Working Hard: Explaining Hours Worked Differences in the US and Germany. Labour Econ. 2001, 8, 181-202. [CrossRef]

62. Sparks, K.; Cooper, C.; Fried, Y.; Shirom, A. The Effects of Hours of Work on Health: A Meta-Analytic Review. J. Occup. Organ. Psychol. 1997, 70, 391-408. [CrossRef]

63. Spurgeon, A.; Harrington, J.M.; Cooper, C.L. Health and Safety Problems Associated with Long Working Hours: A Review of the Current Position. Occup. Environ. Med. 1997, 54, 367-375. [CrossRef]

64. Boyd, R.; Holton, R.J. Technology, Innovation, Employment and Power: Does Robotics and Artificial Intelligence Really Mean Social Transformation? J. Sociol. 2018, 54, 331-345. [CrossRef]

65. Cockburn, I.M.; Henderson, R.; Stern, S. The Impact of Artificial Intelligence on Innovation; National Bureau of Economic Research: Cambridge, MA, USA, 2018.

66. Helbing, D.; Frey, B.S.; Gigerenzer, G.; Hafen, E.; Hagner, M.; Hofstetter, Y.; van den Hoven, J.; Zicari, R.V.; Zwitter, A. Will Democracy Survive Big Data and Artificial Intelligence? In Towards Digital Enlightenment: Essays on the Dark and Light Sides of the Digital Revolution; Helbing, D., Ed.; Springer: Cham, Switzerland, 2019; pp. 73-98, ISBN 978-3-319-90869-4.

67. Swartz, D.L. Bringing Bourdieu's Master Concepts into Organizational Analysis. Theory Soc. 2008, 37, 45-52. [CrossRef]

68. Bourdieu, P. Outline of a Theory of Practice; Cambridge University Press: Cambridge, UK, 1977; ISBN 978-0-521-29164-4.

69. Power, E.M. An Introduction to Pierre Bourdieu's Key Theoretical Concepts. J. Study Food Soc. 1999, 3, 48-52. [CrossRef]

70. Othman, A.K.; Mahmud, Z.; Noranee, S.; Noordin, F. Measuring Employee Happiness: Analyzing the Dimensionality of Employee Engagement. In Proceedings of the 7th International Conference on Kansei Engineering and Emotion Research 2018; Lokman, A.M., Yamanaka, T., Lévy, P., Chen, K., Koyama, S., Eds.; Springer: Singapore, 2018; pp. 863-869.

71. Saari, L.M.; Judge, T.A. Employee Attitudes and Job Satisfaction. Hum. Resour. Manag. 2004, 43, 395-407. [CrossRef]

72. Jost, J.T. The IAT Is Dead, Long Live the IAT: Context-Sensitive Measures of Implicit Attitudes Are Indispensable to Social and Political Psychology. Curr. Dir. Psychol. Sci. 2019, 28, 10-19. [CrossRef]

73. Perugini, M. Predictive Models of Implicit and Explicit Attitudes. Br. J. Soc. Psychol. 2005, 44, 29-45. [CrossRef] [PubMed]

74. Kock, F.; Berbekova, A.; Assaf, A.G. Understanding and Managing the Threat of Common Method Bias: Detection, Prevention and Control. Tour. Manag. 2021, 86, 104330. [CrossRef]

75. Biernacki, P.; Waldorf, D. Snowball Sampling: Problems and Techniques of Chain Referral Sampling. Sociol. Methods Res. 1981, 10, 141-163. [CrossRef]

76. Emerson, R.W. Convenience Sampling, Random Sampling, and Snowball Sampling: How Does Sampling Affect the Validity of Research? J. Vis. Impair. Blind. 2015, 109, 164-168. [CrossRef]

77. Bosnjak, M.; Tuten, T.L. Prepaid and Promised Incentives in Web Surveys: An Experiment. Soc. Sci. Comput. Rev. 2003, 21, 208-217. [CrossRef] 
78. Deutskens, E.; de Ruyter, K.; Wetzels, M.; Oosterveld, P. Response Rate and Response Quality of Internet-Based Surveys: An Experimental Study. Mark. Lett. 2004, 15, 21-36. [CrossRef]

79. Cobb-Clark, D.A.; Schurer, S. The Stability of Big-Five Personality Traits. Econ. Lett. 2012, 115, 11-15. [CrossRef]

80. Reifman, A.; Arnett, J.J.; Colwell, M.J. Emerging Adulthood: Theory, Assessment and Application. J. Youth Dev. 2007, 2, 37-48. [CrossRef]

81. Featherstone, M. Lifestyle and Consumer Culture. Theory Cult. Soc. 1987, 4, 55-70. [CrossRef]

82. Maguire, J.S.; Matthews, J. Cultural Intermediaries and the Media. Sociol. Compass 2010, 4, 405-416. [CrossRef]

83. Brougham, D.; Haar, J. Smart Technology, Artificial Intelligence, Robotics, and Algorithms (STARA): Employees' Perceptions of Our Future Workplace. J. Manag. Organ. 2018, 24, 239-257. [CrossRef]

84. Minsky, M. The Emotion Machine: Commonsense Thinking, Artificial Intelligence, and the Future of the Human Mind; Simon and Schuster: New York, NY, USA, 2007; ISBN 978-0-7432-7664-1. 